\title{
Pola Asuh Efektif untuk Anak Berkebutuhan Khusus di Era Digital
}

\author{
${ }^{1}$ Nailis Saadah, ${ }^{1}$ Kholida Firdausia, ${ }^{2}$ Naila Afrida, ${ }^{3}$ Yunis Widyaningrum, \\ ${ }^{3}$ Muhammad Shofiyuddin, ${ }^{4}$ Muhammad Nofan Zulfahmi* \\ ${ }^{1}$ Pendidikan Guru Sekolah Dasar, Universitas Islam Nahdlatul Ulama Jepara, Indonesia \\ ${ }^{2}$ Pendidikan Agama Islam, Universitas Islam Nahdlatul Ulama Jepara, Indonesia \\ ${ }^{3}$ Pendidikan Bahasa Indonesia, Universitas Islam Nahdlatul Ulama Jepara, Indonesia \\ ${ }^{4}$ Pendidikan Guru PAUD, Universitas Islam Nahdlatul Ulama Jepara, Indonesia \\ *Corresponding Author \\ Jl. Taman Siswa (Pekeng) Tahunan Jepara 59427, (0291) 595320 / (0291) 592630 \\ E-mail: Nofan@unisnu.ac.id \\ Received: Revised: Accepted: Published: \\ 20 April $2021 \quad 12$ October $2021 \quad 17$ November 202119 November 2021
}

\begin{abstract}
Abstrak
Desa Purwogondo memiliki Yayasan Cinta Harapan Indonesia (YCHI) yang bergerak di bidang lembaga pendidikan. YCHI ingin menjadi pusat yang terunggul dan terdepan dalam penanganan autisma berbasis Applied Behavior Analysis melalui pendidikan, pelatihan keterapian dan penelitian. Tujuan pengabdian ini yaitu, membangun relasi yang hangat antara orang tua dan anak melalui penerimaan, kepedulian dan sikap responsif terhadap kebutuhan anak serta adanya batasan-batasan yang diwujudkan melalui tuntutan dan kontrol di era digital. Metode yang digunakan adalah dengan persiapan, pelaksanaan dan evaluasi. Berdasarkan hasil evaluasi kegiatan diperoleh hasil data secara garis besar setelah dilaksanakan kegiatan pengabdian kepada masayarakat, pemahaman orang tua terkait pola asuh efektif untuk anak berkebutuhan khusus di era digital berhasil dipahami dengan baik. Simpulannya adalah kegiatan pengabdian ini berjalan dengan lancar sehingga ada respon yang baik dari orang tua agar dapat menerapkan pola asuh efektif untuk anak berkebutuhan khusus di era digital untuk kedepannya. Oleh karena itu, orang tua harus mampu menerapkan pola asuh yang efektif sesuai dengan perkembangan zaman.
\end{abstract}

Kata Kunci: Anak Berkebutuhan Khusus; Era Digital; Pola Asuh

\begin{abstract}
Purwogondo village has the Yayasan Cinta Harapan Indonesia YCHI which is engaged in educational institutions. YCHI wants to be the center of excellence and foremost in the treatment of autism based on Applied Behavior Analysis through education, therapeutic training and research. The purpose of this service is to build a warm relationship between parents and children through acceptance, care and responsiveness to children's needs and the existence of boundaries that are realized through demands and controls in the digital era. The method used is the preparation, implementation and evaluation. Based on the results of the activity evaluation, it was obtained that after the community service activities were carried out, the understanding of parents regarding effective parenting for children with special needs in the digital era was well understood. The conclusion is that this service activity runs smoothly so that there is a good response from parents so that they can implement effective parenting for children with special needs in the digital era in the future. Therefore, parents must be able to apply effective parenting in accordance with the times.
\end{abstract}

Keywords: Children with Special Needs; Digital Era; Parenting 


\section{PENDAHULUAN}

YCHI (Yayasan Cinta Harapan Indonesia) didirikan karena mempunyai keinginan untuk memberikan harapan kepada para orang tua dari anak berkebutuhan khusus yang sebelumnya bahkan tidak bisa membayangkan bagaimana memberikan penanganan kepada anak mereka. Riadin (2017) menjelaskan sbahwasanya anak berkebutuhan khusus yaitu anak yang mengalami gangguan fisik, mental, inteligensi dan emosi sehingga membutuhkan pembelajaran secara khusus. Sejalan dengan latar belakang didirikannya YCHI ini, pendidikan memang sangat dibutuhkan oleh seorang anak. Mareza (2016) juga mengungkapkan bahwasanya pendidikan adalah hak asasi yang paling mendasar bagi setiap manusia, tidak terkecuali bagi anak luar biasa atau anak berkebutuhan khusus.

Berdasarkan hasil observasi yang telah dilakukan, ditemukan beberapa kendala yang menjadi pokok permasalahan di YCHI, salah satunya yaitu kurangnya kesadaran tentang pola asuh orang tua terhadap perkembangan anak. Permasalahan ini merupakan permasalahan yang sangat signifikan, karena keluarga khususnya orang tua merupakan wahana utama dalam pembentukan karakter atau perkembangan anak. Amelasasih (2016) menjelaskan bahwasanya orang tua memiliki tanggung jawab yang besar terhadap anak khususnya bagi anak berkebutuhan khusus. Pertama, orang tua yang memiliki anak berkebutuhan khusus mempunyai tanggung jawab sebagai penentu keputusan sebab orang tua yang menentukan alternatif mana yang nantinya akan ditempuh oleh anak. Kedua, orang tua memerlukan penyesuaian diri dengan keadaan serta sosialisasi kepdada anak. Ketiga, orang tua sebagai pendidik dari anaknya bukan merupakan pendidik anak berkebutuhan khusus yang professional, melainkan orang tua yang dapat berperan memberikan beberapa stimulasi dan pelatihan pada aspek-aspek perkembangan tertentu sebatas kemampuan yang dimiliki orang tua. Keempat, orang tua juga mempunyai tanggung jawab sebagai advocate, yaitu sebagai pendukung serta pembela kepentingan dan kebutuhan anaknya yang berkebutuhan khusus. Berdasarkan permasalahan tersebut maka dibutuhkanlah adanya penyuluhan mengenai pola asuh efektif untuk anak berkebutuhan khusus terutama pada era digital.

Sebagaimana yang diungkapkan oleh Rahmat (2018) dalam penelitiannya yang berjudul "Pola Asuh yang Efektif untuk Mendidik Anak di Era Digital" bahwasanya keluarga sebagai locus pembentukan karakter anak perlu mengembangkan pola asuh yang edukatif dan efektif. Pola asuh tersebut berupaya untuk membantu anak agar bersikap kritis terhadap pengaruhpengaruh negatif dari era digital. Sejalan dengan hal tersebut, Lubis (2019) dalam penelitiannya yang berjudul "Pola Asuh Efektif di Era Digital" mengungkapkan bahwa di era digital saat ini para orang tua harus memilih pola asuh yang efektif untuk anak agar terhindar dari perilaku menyimpang. Ditinjau dari pendapat para ahli tersebut, maka disimpulkan bahwa pola asuh yang diberikan orang tua sangat berpengaruh terhadap perkembangan anak. Oleh karena itu, orang tua harus menerapkan pola asuh efektif yang sesuai dengan perkembangan zaman.

Tujuan dari pengabdian ini yaitu, mampu membangun relasi yang hangat antara orang tua dan anak melalui penerimaan, kepedulian dan sikap responsif terhadap kebutuhan anak serta adanya batasan-batasan yang diwujudkan melalui tuntutan dan kontrol.

\section{METODE PELAKSANAAN}

Pengabdian ini dilaksanakan pada Sabtu, 06 Maret 2021 di YCHI Purwogondo Kalinyamatan Jepara. Berdasarkan permasalahan yang telah dipaparkan, solusi yang dapat diberikan yaitu mengadakan penyuluhan tentang pola asuh efektif untuk anak berkebutuhan khusus di era digital. Dengan harapan agar mampu menambah wawasan orang tua mengenai cara pola asuh yang positif. Adapun tahap pelaksanan pengabdian ini meliputi: 
Tabel 1. Tahapan Pelaksanaan Kegiatan

\begin{tabular}{|c|c|c|}
\hline No & Tahapan & Kegiatan \\
\hline 1 & Persiapan & $\begin{array}{l}>\text { Koordinasi dengan mitra dan DPL } \\
>\text { Pembagian tugas tiap anggota } \\
>\text { Menentukan Narasumber } \\
\text { Menyiapkan perlengkapan yang } \\
\text { diperlukan untuk kegiatan } \\
\text { penyuluhan. }\end{array}$ \\
\hline 2 & Pelaksanaan & $\begin{array}{l}\text { Penyampaian materi penyuluhan } \\
\text { tentang pola asuh efektif untuk anak } \\
\text { berkebutuhan khusus di era digital. }\end{array}$ \\
\hline 3 & Evaluasi & $\begin{array}{l}\text { Evaluasi hasil kerja untuk mengetahui } \\
\text { permasalahan setelah adanya kegiatan } \\
\text { penvuluhan. }\end{array}$ \\
\hline
\end{tabular}

Sumber: Tim Pengabdi, 2021

Kegiatan pengabdian ini ditujukan untuk orang tua peserta didik dimana mereka sangat membutuhkan arahan agar mampu memberikan pola asuh yang tepat untuk anaknya di era digital. Penyampaian materi pada penyuluhan ini disampaikan oleh narasumber yang sudah berpengalaman dalam menangani anak berkebutuhan khusus yaitu, Ibu Hamidaturrohmah selaku dosen di UNISNU jepara. Tenaga pendidik dan orang tua sangat berpartisipasi dengan baik dalam mengikuti kegiatan ini.

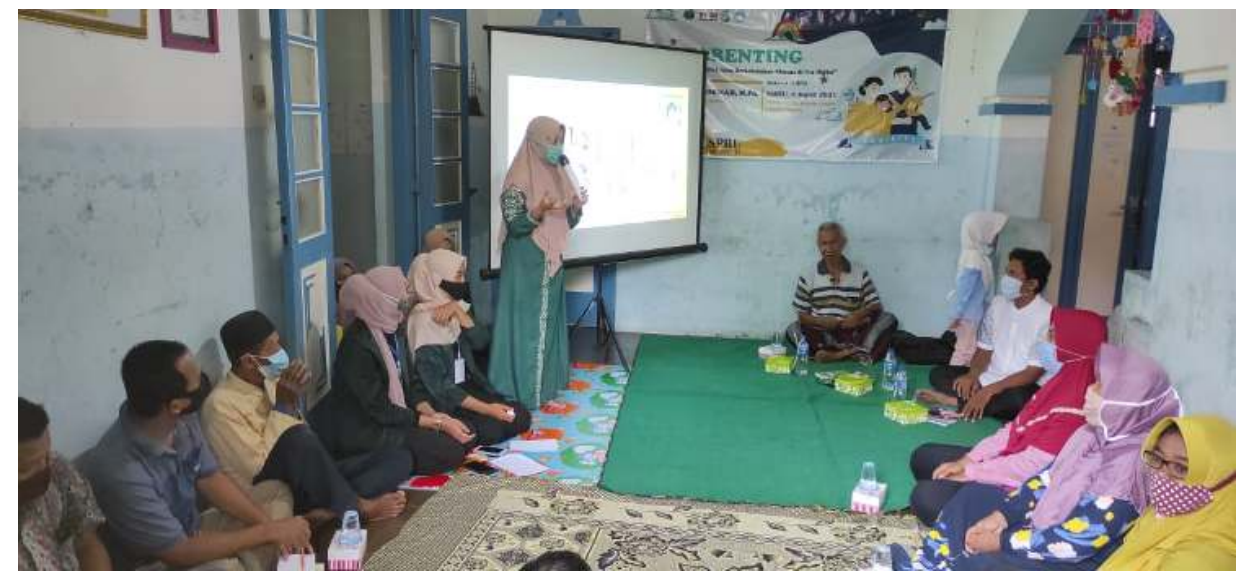

Gambar 1. Kegiatan Penyuluhan Bersama Ibu Hamidaturrohmah

\section{HASIL DAN PEMBAHASAN}

Orang tua memiliki peranan penting dalam mendidik dan mengasuh anak. Setiap anak memiliki karakteristik yang berbeda-beda, sehingga pola asuhnya pun berbeda. Begitu pun dengan Anak Berkebutuhan Khusus (ABK). Mereka memerlukan penanganan dan pola asuh yang tepat. Pola asuh sendiri berarti kemampuan dasar keluarga dalam memberikan perhatian dan dukungan terhadap setiap aspek perkembangan anak baik secara fisik, mental dan sosial. Pola asuh yang tepat sangat penting agar anak dapat memiliki tumbuh kembang yang baik.

Sejalan dengan hal tersebut, Devi (2015) dalam penelitiannya yang berjudul "Pola Asuh Orang Tua dan Pola Pendidikan di Sekolah dalam Pembentukan Kemandirian Anak Tunagrahita" mengungkapkan bahwa anak tunagrahita atau anak-anak berkebutuhan khusus lainnya butuh perhatian khusus dari keluarga, sekolah maupun lingkungan sekitar lebih dari 
perhatian pada anak-anak normal lainnya. Masa anak-anak sebagian besar menghabiskan waktu bersama keluarga, maka dari itu keluarga berperan penting terhadap masa depan anak, begitu pula perkembangan anak dilihat dari perkembangan fisik, psikis sosial, dan religius moral agama juga dipengaruhi oleh keluarga. Cara memahami anak salah satunya adalah dengan memberikan praktik pola asuh yang sesuai dan baik. Selain pola asuh orang tua, sekolah merupakan lembaga pendidikan formal yang melaksanakan program pendampingan, bimbingan, pengajaran serta latihan-latihan dalam memfasilitasi anak agar dapat mengembangkan potensi diri, baik yang terkait aspek moral spiritual, intelaktual, emosional maupun sosial. Mengenai peran sekolah dalam rangka pengembangan kepribadian anak, Hurlock mengungkapkan bahwa sekolah adalah faktor penentu bagi perkembangan kepribadian anak (siswa), baik dalam segi berfikir, bersikap maupun cara berperilaku.

Cara menerapkan pola asuh yang tepat menurut Hamidaturrohmah dalam kegiatan penyuluhan pola asuh efektif untuk anak berkebutuhan khusus di era digital dapat dilakukan melalui tiga aspek yaitu secara mental, secara sosial dan secara fisik. Pola asuh secara mental dan secara sosial dapat dilakukan oleh orang tua anak berkebutuhan khusus dengan cara berikut ini:

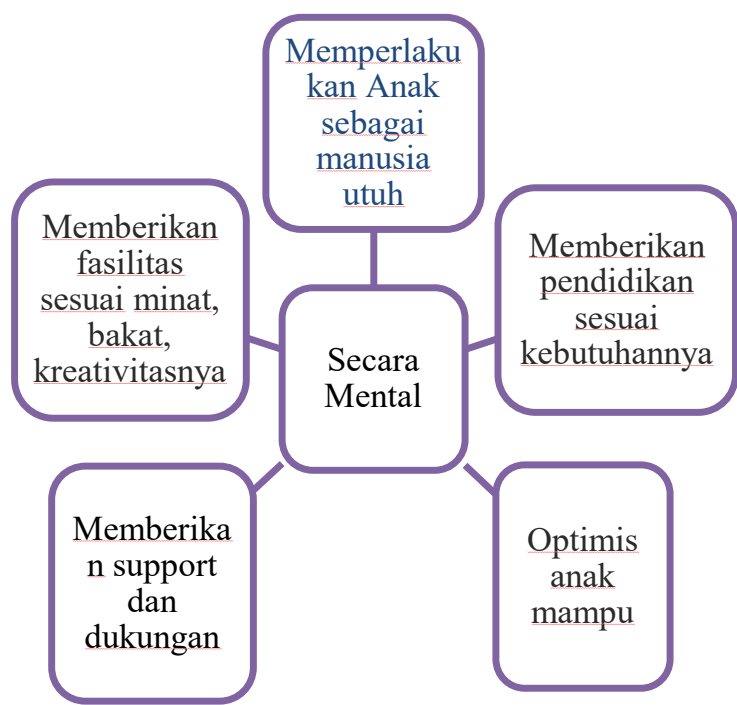

Gambar 2. Pola Asuh Secara Mental 


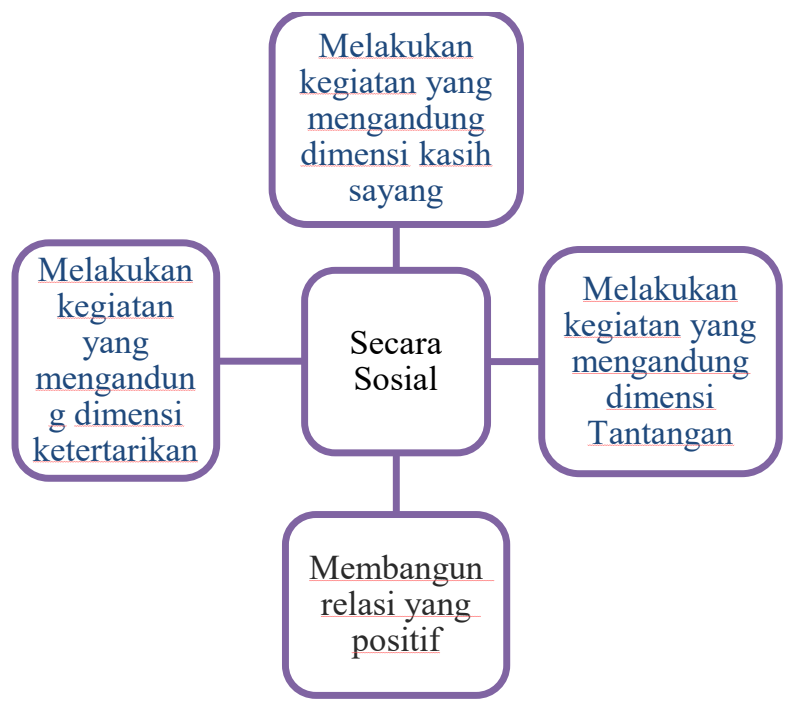

Gambar 3. Pola Asuh Secara Sosial

Pola asuh secara fisik diterapkan dengan menjaga pola makan anak dan memberikan makanan yang utuh dan sehat. Ada beberapa hal yang harus dihindari oleh anak autism, diantaranya:

1. Mengonsumsi susu (kasein), produk olahan serta turunannya

2. Mengonsumsi terigu (gluten), produk olahan serta turunannya

3. Mengonsumsi semua jenis gula

4. Mengonsumsi kedelai (soya), produk olahan serta turunannya

5. Mengonsumsi bahan kimia buatan, seperti pewarna makanan, perasa makanan dan pengawet makanan

Hal lain diungkapkan oleh Suchyadi (2018) dalam penelitiannya yang berjudul "Pola Asuh Orang Tua terhadap Anak Tunanetra Berprestasi Usia Sekolah Dasar" bahwa ada hubungan antara pola pengasuhan orang tua terhadap anak tunanetra dengan prestasi belajar tunanetra. Pola asuh merupakan potensi besar yang membentuk pencapaian anak tunanetra. Bukan hanya satu bentuk pengasuhan, tetapi terdiri dari beberapa pola pengasuhans, termasuk pola asuh demokrasi, pengasuhan laissez faire, pengasuhan yang melelehkan diri sendiri, pola asuh yang memanipulasi pola pengasuhan, pola asuh atas peran dan pola asuh konsultan.

Berdasarkan penelitian dan pengalaman yang dilakukan oleh dr Rudy selama puluhan tahun bahwa anak autism yang mengonsumsi telur, ikan laut dan hewan laut lainnya menunjukkan perburukan perilaku dan dapat berpengaruh buruk pada sistem saluran cerna, daya tahan tubuh, sistem endoktrin dan sistem saraf anak autism. Pengaturan pola makan tersebut dapat dibuat ke dalam jadwal makanan yang mengharuskan ABK untuk diet. 
Tabel 2. Jadwal Makanan

\begin{tabular}{|c|c|c|c|c|c|c|c|}
\hline & Senin & Selasa & Rabu & Kamis & Jumat & Sabtu & Ahad \\
\hline Daging & Bebek & $\begin{array}{c}\text { Ayam } \\
\text { Organik }\end{array}$ & Sapi & Kambing & Puyuh & Kerbau & Kelinci \\
\hline Ikan & Lele & Mujair & Gurame & Nila & Ikan Mas & Patin & Bawel \\
\hline Sayur & $\begin{array}{l}\text { Sawi } \\
\text { Hijau }\end{array}$ & $\begin{array}{l}\text { Sawi } \\
\text { Putih }\end{array}$ & Labu Siam & Pockcoy & $\begin{array}{l}\text { Kacang } \\
\text { Panjang }\end{array}$ & Tauge & Buncis \\
\hline Buah & $\begin{array}{c}\text { Daging } \\
\text { Kelapa } \\
\text { Muda }\end{array}$ & $\begin{array}{c}\text { Jambu Air } \\
\text { Hijau }\end{array}$ & Bengkuang & $\begin{array}{c}\text { Jambu } \\
\text { Biji } \\
\text { Kristal }\end{array}$ & Markisa & Srikaya & Sirsak \\
\hline Minyak & Canola & $\begin{array}{c}\text { Lemak } \\
\text { Ayam }\end{array}$ & $\begin{array}{c}\text { Lemak } \\
\text { Sapi }\end{array}$ & $\begin{array}{l}\text { Rice } \\
\text { Brand }\end{array}$ & $\begin{array}{c}\text { Minyak } \\
\text { Sawit }\end{array}$ & $\begin{array}{c}\text { Minyak } \\
\text { Kelapa }\end{array}$ & $\begin{array}{c}\text { Minyak } \\
\text { Biji } \\
\text { Bunga } \\
\text { Matahari }\end{array}$ \\
\hline Bumbu & Seledri & Kemangi & $\begin{array}{l}\text { Daun } \\
\text { Salam }\end{array}$ & Lengkuas & $\begin{array}{c}\text { Bawang } \\
\text { Putih }\end{array}$ & $\begin{array}{c}\text { Daun } \\
\text { Bawang }\end{array}$ & $\begin{array}{l}\text { Daun } \\
\text { Salam }\end{array}$ \\
\hline
\end{tabular}

Hamidaturrohmah juga menyebutkan pola asuh orang tua meliputi tiga hal yaitu penerimaan orang tua terhadap kondisi anak, tuntutan orang tua dan gaya pengasuhan orang tua yang bervariasi. Gaya pengasuhan orang tua diantaranya:

1. Pola Asuh Otoriter

Sikap orang tua yang memiliki pola asuh otoriter adalah memiliki sikap penerimaan yang rendah namun kontrolnya tinggi, suka menghukum secara fisik, bersikap mengomando (mengharuskan atau memaksa anak melakukan sesuatu tanpa kompromi), bersikap kaku (keras) dan emosional. Sikap orang tua seperti itu sangat tidak disarankan karena perilaku anak akan cenderung temperamental, tidak tenang, tidak memiliki tujuan, penuh ketakutan, mudah stress dan tidak percaya diri.

2. Pola Asuh Demokratis

Pola asuh demokratis yaitu mengarahkan anak secara rasional, selalu bersikap terbuka dan mengajari anak untuk selalu hidup mandiri. Pola asuh demokratis ini mampu menciptakan keseimbangan antara hak dan kewajiban orang tua dan anak sehingga anak dapat bertanggung jawab atas tindakan yang dilakukan.

3. Pola Asuh Permisif

Pola asuh permisif berarti menerima dengan secara terbuka kemauan anak tapi kepada hal yang positif yang anak kerjakan. Tipe ini juga orang tua sangat longgar kepada anak sehingga anak diberi kebebasan semuanya atau orang tua terlalu memanjakannya.

Sejalan dengan hal tersebut, Khotimah (2019) dalam penelitiannya yang berjudul "Hubungan Pola Asuh Orang Tua dalam Penggunaan Gadget dengan Perkembangan SosialEmosional Anak Prasekolah (3-6 Tahun) di TK Al-Hidayah Plus Madiun" menjelaskan bahwasanya pola asuh yang paling ideal dan efektif di era digital adalah pola asuh demokratis. Tipe pola asuh ini tiddak mensteril anak dari pengaruh era dgital, tetapi berupaya menguatkan anak agar bersikap kritis terhadap pengaruh positif dan negatif era digital. Tipe orang tua demokratis memiliki anak-anak yang merasa bahagia secara batin, kompeten dalam bidangnya dan sukses dalam pengertian bahwa mampu beradaptasi serta msenjalin hubungan baik dengan orang lain. Hal lain juga dijelaskan oleh Aslan (2019) dalam penelitiannya yang berjudul "Peran 
Pola Asuh Orang Tua di Era Digital" bahwa orang tua harus menggunakan ketiga pola asuh tersebut untuk mengetahui perkembangan anak. Ketiga pola asuh tersebut diberlakukan kepada anak sesuai dengan situasi dan kondisi yang diperlukan.

Kepribadian anak sangat dipengaruhi oleh peranan dalam keluarga. Keluarga dipandang sebagai lembaga yang dapat memenuhi kebutuhan para anggotanya terutama kebutuhan dalam mengembangkan kepribadian para anggotanya agar bisa menjadi pribadi yang memiliki sikap baik dan bisa menjadi anggota masyarakat yang baik. Setiap anggota keluarga memiliki peranan pribadi masing-masing, peranan pribadi dalam keluarga didasari oleh harapan dan pola perilaku dari keuarga, kelompok dan masyarakat. Sejalan dengan hal tersebut, Mufidah (2019) dalam penelitiannya yang berjudul "Pola Asuh Orang Tua terhadap Anak Berkebutuhan Khusus di SD SLB Negeri Kroya Kabupaten Cilacap" menjelaskan bahwa pola asuh yang diberikan oleh orang tua yang memiliki anak berkebutuhan khusus adalah demokratis yang ditandai adanya bimbingan, arahan, hubungan timbal balik antara orang tua dan anak. Orang tua selalu meneruskan program yang diajarkan di sekolah untuk diterapkan di rumah. Orang tua selalu mengajarkan pengembangan diri di rumah agar anak mandiri, namun ketika di sekolah orang tua lebih banyak membantu anaknya dengan mengambil alih pekerjaannya jika mengalami kesulitan. Sedangkan hambatan yang dialami oleh orang tua dalam melakukan pola asuh terhadap anak berkebutuhan khusus adalah faktor kestabilan emosi orang tua dan keterbatasan yang dimiliki anak.

Cara mendidik anak di era digital menurut Hamidaturrohmah yaitu, menggunakan media teknologi untuk menstimulasi perkembangan anak, selalu mengontrol anak, mendampingi belajar dan media untuk menjalin relasi yang hangat dalam menumbuhkan kreativitas. Orang tua harus yakin dan percaya bahwa anak berkebutuhan khusus itu bisa. Jadi anak berkebutuhan khusus akan lebih berkembang dengan baik. Berdasarkan hasil evaluasi kegiatan diperoleh data secara garis besar kegiatan pengabdian kepada masayarakat terkait Pola Asuh Efektif untuk Anak Berkebutuhan Khusus di Era Digital berhasil dilaksanakan dengan baik. Hal ini dibuktikan dengan sebelumnya masih banyak orang tua yang belum mengetahui terkait pola asuh efektif. Target yang diinginkan dalam kegiatan pelatihan ini tercapai. Hal tersebut peserta sudah mampu berhasil memahami tentang Pola Asuh Efektif untuk Anak Berkebutuhan Khusus di Era Digital sesudah mengikuti sajian materi dan penyuluhan yang disampaikan. Orang tua sudah dapat membedakan macam-macam pola

\section{KESIMPULAN}

Setiap orang tua pasti menginginkan seorang anak untuk melengkapi hidupnya. Orang tua mengharapkan anak yang dilahirkan normal atau tidak berkebutuhan khusus, namun tidak semua anak yang lahir ke dunia dalam keadaan sehat sempurna, beberapa diantaranya terlahir dalam kondisi yang memiliki kekurangan baik secara fisik maupun psikis atau yang biasa disebut anak berkebutuhan khusus. Keluarga memiliki peran yang sangat penting dalam mendidik anak terutama pada anak berkebutuhan khusus. Peran keluarga sangat dibutuhkan oleh anak berkebutuhan khusus agar anak dapat berkembang dengan baik. Dukungan orang tua pada anak berkebutuhan khusus juga sangat dibutuhkan agar anak memiliki rasa percaya diri, kemampuan dan kemandirian yaitu dengan cara memberikan pola asuh yang harus disesuaikan dengan kondisi anak agar anak dapat tumbuh dan berkembang menjadi pribadi yang lebih baik, mandiri dan memiliki kepercayaan diri walaupun dengan penuh keterbatasan.

Peran orang tua dalam mendidik anak tidak terlepas dari pola asuh yang diterapkan oleh orang tua. Era digital saat ini, dengan berbagai macam kecanggihan teknologi, tipe pola asuh orang tua kepada anak mengalami perubahan. Tipe pola asuh yang terdiri dari otoriter, 
demokrasi dan permisif yang diberikan oleh orang tua dengan sistem pola asuh yang berbedabeda kepada anak, maka akan menghasilkan karakter yang berbeda-beda juga kepada anak khususnya bagi anak berkebutuhan khusus. Oleh karena itu, orang tua harus mampu menerapkan pola asuh yang efektif sesuai dengan perkembangan zaman.

\section{UCAPAN TERIMA KASIH}

Ucapan terimakasih disampaikan kepada Lembaga Penelitian dan Pengabdian Masyarakat (LPPM) Universitas Islam Nahdlatul ulama Jepara (UNISNU) yang telah memberikan dukungan berupa biaya dan motivasi, Yayasan Cinta Harapan Indonesia (YCHI) Purwogondo yang telah memfasilitasi kegiatan ini, Narasumber penyuluhan "Pola Asuh Efektif untuk Anak Berkebutuhan Khusus di Era Digital" yaitu Ibu Hamidaturrohmah, M.Pd., dan seluruh tamu undangan dan panitia yang begitu antusias dalam mengikuti kegiatan ini.

\section{DAFTAR PUSTAKA}

Amelasasih, P. (2016). Resiliensi Orang Tua yang Mempunyai Anak Berkebutuhan Khusus. PSIKOSAINS. 11 (2): 72-81. http://dx.doi.org/10.30587/psikosains.v11i2.638

Aslan. (2019). Peran Pola Asuh Orang Tua di Era Digital. Jurnal Studia Insania. 7 (1): 20-34. https://dx.doi.org/10.18592/jsi.v7i1.2269

Devi, G. P. (2015). Pola Asuh Orang Tua dan Pola Pendidikan di Sekolah dalam Pembentukan Kemandirian Anak Tunagrahita. Jurnal Al-Shifa. 5 (2): 209-221. http://etheses.uinmalang.ac.id/1505/12/11410069_Ringkasan.pdf

Khotimah, A. N. (2019). Hubungan Pola Asuh Orang Tua dalam Penggunaan Gadget dengan Perkembangan Sosial-Emosional Anak Prasekolah (3-6 Tahun) di TK Al-Hidayah Plus Madiun. Skripsi.

Lubis, H. d. (2019). Pola Asuh Efektif di Era Digital. Jurnal Pelayanan Kepada Masyarakat. 1 (2): 102-109. http://dx.doi.org/10.30872/plakat.v1i2.2967

Mareza, L. (2016). Pengajaran Kreativitas Anak Berkebutuhan Khusus pada Pendidikan Inklusi. Jurnal Indigenous. 1 (2): 99-105. https://doi.org/10.23917/indigenous.v1i1.2764

Mufidah, P. A. (2019). Pola Asuh Orang Tua terhadap Anak Berkebutuhan Khusus di SD SLB Negeri Kroya Kabupaten Cilacap. Skripsi.

Rahmat, S. T. (2018). Pola Asuh yang Efektif untuk Mendidik Anak di Era Digital. Jurnal $\begin{array}{lllll}\text { Pendidikan dan Kebudayaan } & \text { Missio. } 10 & \text { (2): }\end{array}$ http://jurnal.unikastpaulus.ac.id/index.php/jpkm/article/view/166

Riadin, A. d. (2017). Karakteristik Anak Berkebutuhan Khusus di Sekolah Dasar Negeri (Inklusi) di Kota Palangka Raya. Anterior Jurnal. 17 (1): 22-27. https://doi.org/10.33084/anterior.v17i1.17

Suchyadi, S. S. (2018). Pola Asuh Orang Tua terhadap Anak Tuna Netra Berprestasi Usia Sekolah Dasar. Jurnal Pendidikan \& Pengajaran Guru Sekolah Dasar. 1 (1): 99-108. http://dx.doi.org/10.30587/psikosains.v11i2.638 